\title{
A CONSTITUIÇÃO DA EDUCAÇÃO ESCOLAR MODERNA: DO VIÉS EMANCIPADOR À ESTAGNAÇÃO CONSERVADORA
}

\author{
THE CONSTITUTION OF MODERN SCHOOL EDUCATION: FROM \\ EMANCIPATING BIAS TO CONSERVATIVE STAGNATION
}

\section{LA CONSTITUCIÓN DE LA EDUCACIÓN ESCOLAR MODERNA: DEL SESGO EMANCIPADOR AL ESTANCAMIENTO CONSERVADOR}

DOI: http://dx.doi.org/10.9771/gmed.v11i3.33904

Fernanda Bartoly Gonçalves de Lima ${ }^{1}$

\begin{abstract}
Resumo: O presente artigo busca resgatar a compreensão histórica da constituição da escola moderna como forma dominante de educação, problematizando os rumos ideológicos tomados a partir do período no qual a classe burguesa se consolida como classe dominante. Para isso, se realiza uma pesquisa de cunho teórico, na perspectiva materialista histórica dialética, demonstrando como a prerrogativa da emancipação se apresenta nesse primeiro momento de constituição revolucionária e em um posterior momento de decadência ideológica. Defende-se que uma compreensão maior acerca desses processos conservadores poderia, além de ampliar a percepção do que ocorre hoje no âmbito da atual retomada conservadora, auxiliar a resgatar a potencialidade revolucionária da educação escolar, que se materializa na socialização do conhecimento socialmente acumulado. Entende-se que o conhecimento, em sua radicalidade histórica, é substancial para a formação do sujeito revolucionário - o sujeito que concentra as condições subjetivoobjetivas para a luta pela emancipação humana.
\end{abstract}

Palavras-chave: educação escolar, emancipação, correntes pedagógicas.

Abstract: This article seeks to recover the historical understanding of the constitution of the modern school as a dominant form of education, problematizing the ideological directions taken from the period in which the bourgeois class consolidates itself as the ruling class. To this end, a theoretical research is conducted from the dialectical historical materialist perspective, showing how the prerogative of emancipation is presented in this first moment of revolutionary constitution and in a later moment of ideological decay. It is argued that a greater understanding of these conservative processes could, in addition to broadening the perception of what is happening today within the current conservative resumption, help to rescue the revolutionary potentiality of school education, which materializes in the socialization of socially accumulated knowledge. Knowledge, in its historical radicality, is understood to be substantial for the formation of the revolutionary subject - the subject who concentrates the subjective-objective conditions for the struggle for human emancipation.

Keywords: school education, emancipation, pedagogical currents.

Resumen: Este artículo busca recuperar la comprensión histórica de la constitución de la escuela moderna como una forma dominante de educación, problematizando las direcciones ideológicas tomadas desde el período en que la clase burguesa se consolida como la clase dominante. Con este fin, se realiza una investigación teórica desde la perspectiva materialista histórica dialéctica, que muestra cómo se presenta la prerrogativa de la emancipación en este primer momento de constitución revolucionaria y en un momento posterior de decadencia ideológica. Se argumenta que una mayor comprensión de estos procesos conservadores podría, además de ampliar la percepción de lo que ocurre hoy dentro de la reanudación conservadora actual, ayudar a rescatar la potencialidad revolucionaria de la educación escolar, que se materializa en la socialización del conocimiento socialmente acumulado. Se entiende que el conocimiento, en su radicalidad histórica, es sustancial para la formación del sujeto revolucionario, el sujeto que concentra las condiciones subjetivas-objetivas para la lucha por la emancipación humana.

Palabras clave: educación escolar, emancipación, corrientes pedagógicas. 


\section{Introdução}

O processo educativo, ao longo da história, se origina das necessidades desenvolvidas pela sociedade, sendo, juntamente ao trabalho, uma atividade fundamental à humanidade: "a educação é um complexo universal, comparecendo em todas as formas de sociedade constituídas pelo homem" (LIMA, 2009, p. 109). Desta forma, sua relação com o trabalho, como atividade que funda o ser social, é de profunda correspondência. O desenvolvimento humano alcançado pelo trabalho, e pelas metamorfoses do mundo do trabalho, promovem as transformações no processo educativo. Este, por sua vez, assegura e consolida o progresso social já alcançado por gerações anteriores, formando a humanidade de acordo com as necessidades sociais.

No início da idade moderna, momento em que revoluções na forma de produção material da vida social precedem revoluções socioeconômicas, ganha vigor uma perspectiva que considera a educação não só como um meio de fomentar a formação humana, mas também para exercer um papel ativo nas transformações sociais. Trata-se de um momento histórico em que a estrutura social passa a ser conscientemente questionada. A organização e a conformação social não são mais vistas como uma ordem divina, e sim relativa à própria humanidade, podendo ser transformada por esta. A burguesia começa a se impor sobre a antiga configuração social, que não mais suportava as necessidades dessa nova forma de produção.

Nesse contexto, a educação é alvo de uma grande expectativa: consolidar as revoluções sociais, sendo o tipo de ser humano que poderia realizar esta tarefa o norte do processo educativo. Com um progresso material realizado pelo desenvolvimento do conhecimento humano, a liberdade se vincula com a possibilidade de a humanidade vir a conhecer este mundo, e, com esse esclarecimento, se emancipar. A partir do momento em que a liberdade se vincula ao conhecimento, a educação é um dos pontos-chave para a emancipação. Assim, a educação é posta como a grande expectativa em prol da transformação social, a libertação da humanidade, e sua emancipação - um intento que foi, posteriormente, reformado e submetido a um propósito conservador.

Desta forma, pela perspectiva materialista histórica dialética, o artigo pretende elucidar as transformações históricas que incidem sobre o complexo educativo, centralizando a escola como a forma social dominante de realização da educação, a partir do momento que o conhecimento demonstra sua potencialidade revolucionária. Em seguida, se discute a expectativa de emancipação pela educação em um momento histórico no qual se busca atenuar as ideias revolucionárias, estabelecendo o modo de produção capitalista como reformável, mas insuperável. Para entender esse período, analisa-se as propostas educacionais de Émile Durkheim (século XIX-XX) que se categorizam o que se entende como pedagogia tradicional moderna, e a oposição reformista deste 
ideário que se expressa no movimento de renovação do ensino Escola Nova (século XX), com destaque para as propostas de John Dewey (1859-1952).

Contestando essas proposições, se busca nas teorias marxianas e marxistas uma compreensão que considera a educação em sua potencialidade revolucionária de corroborar com a emancipação humana. Se entende que o complexo educativo, mesmo sendo determinado pela forma de produção material da vida social, possui uma relação dialética com a sociedade, que permite, nas brechas de suas contradições, atuar de forma subversiva.

\section{Trabalho, educação, escola}

Para uma compreensão congruente com a perspectiva histórica dialética a respeito da educação, é preciso reconhecer esta atividade como um complexo social que surge a partir das necessidades desenvolvidas na atividade trabalho, cumprindo uma determinada função em relação à constituição do ser social. Neste sentido, a educação, assim como o trabalho, é exclusiva à humanidade: "trabalho e educação são atividades especificamente humanas. Isso significa que, rigorosamente falando, apenas o ser humano trabalha e educa” (SAVIANI, 2007, p. 152). É verdade que os outros animais também realizam processos de aprendizados fundamentais para sua sobrevivência, porém, este não os leva para além de sua biologia, de modo que a forma de se relacionar com a natureza permanece, basicamente, a mesma, nas diferentes gerações dos animais não humanos. Ou seja, seu desenvolvimento está profundamente ancorado em sua biologia.

\footnotetext{
Entre os animais, a educação consiste num processo de complementação e atualização de tendências naturais, sempre em consonância com a caracterização da espécie e em conformidade com as determinações do meio, não havendo a mínima possibilidade de ruptura com os padrões naturais de desenvolvimento e reprodução. Trata-se de um processo circunscrito ao âmbito natural, realizado sob os limites dados em cada espécie pelo script geneticamente determinado (LIMA, 2009, p. 106).
}

Mesmo quando um animal consegue aprender elementos para além de sua biologia, como por exemplo no treinamento de cães, este não poderá transmitir sua aprendizagem para os outros animais de sua espécie (ou de qualquer outra), já que o conhecimento não foi por ele apropriado. Pode-se afirmar, nesta acepção, que os animais aprendem, mas não se apropriam de um conhecimento. Se apropriar de algo seria fazer disto um "órgão de sua individualidade" - usando a metáfora de Marx (2008) (DUARTE, 1992) - no qual este não é apenas por ele reproduzido, mas utilizado como ferramenta para sua objetivação enquanto ser singular.

O processo educativo realiza - junto ao trabalho - a própria humanização, que se constitui pelos processos de objetivação e apropriação. Neste sentido, a educação, além de exclusiva à humanidade, também se constitui como uma das atividades indispensáveis à esta. 
Toda sociedade vive porque consome; e para consumir depende da produção. Isto é, do trabalho. Toda a sociedade vive porque cada geração nela cuida da formação da geração seguinte e lhe transmite algo da sua experiência, educa-a. Não há sociedade sem trabalho e sem educação (KONDER, 2000, p. 112).

Elucidando essa questão, parte-se da afirmativa que a humanidade existe e persiste devido a sua produção autogerada, pelo trabalho. No interior do processo de trabalho ocorre não só a objetivação humana, mas também o processo de apropriação dos conhecimentos advindos durante a atividade. Sendo assim, o processo educativo, tal como a atividade trabalho, é imprescindível para que o ser humano se torne humano. Como explica Saviani (2007, p. 154), "a produção do homem é, ao mesmo tempo, a formação do homem, isto é, um processo educativo. A origem da educação coincide, então, com a origem do homem mesmo". A educação surge, portanto, no seio da atividade trabalho, de forma que é possível afirmar que esse complexo possui, em relação ao trabalho, uma dependência ontológica.

A educação está vinculada à forma de realização do trabalho nas diferentes sociedades, logo em profunda relação com o desenvolvimento histórico da humanidade. A ideia do surgimento de uma forma de se efetivar a educação independentemente do modo em que se realiza o trabalho em determinada sociedade seria um contrassenso à perspectiva ontológica da educação. Sob esse ponto de vista:

[...] a educação adquire real significado como objeto da reflexão ontológica somente quando analisada como um dos complexos que compõem o ser da sociedade. [...] Numa primeira aproximação, portanto, é cabível afirmar-se que uma ontologia da educação busca compreender a essência historicamente constituída do processo de formação dos indivíduos humanos como seres sociais. Não se trata de uma essência independente do processo histórico, das formas concretas de educação em cada sociedade (DUARTE, 2012, p. 38).

Sendo um complexo histórico e mediado, a educação se identifica com a necessidade formativa da humanidade em relação à sociedade em que essa se insere: "uma visão histórica da educação mostra como esta esteve sempre preocupada em formar determinado tipo de homem. Os tipos variam de acordo com as diferentes exigências das diferentes épocas" (SAVIANI, 1989, p. 39). Desta forma, a essência do processo educativo se constitui da própria formação humana, esclarecendo que se entende como essência sua característica primordial que é gerada no interior do processo histórico, logo mutável e relativa à história. Ao longo das transformações históricas da forma de realização do trabalho ocorrem as transformações na forma de realização da educação, chegando, inclusive, em configurações que negam à educação a própria formação humana.

$\mathrm{Na}$ direção de uma compreensão do processo de formação humana, e de suas transformações, encontra-se o trabalho como ponto de partida. A educação se origina diretamente de necessidades produzidas no ato histórico do trabalho, não de forma etapista, mas associada.

Diríamos, pois, que no ponto de partida a relação entre trabalho e educação é uma relação de identidade. Os homens aprendiam a produzir sua existência no próprio ato 
de produzi-la. Eles aprendiam a trabalhar trabalhando. Lidando com a natureza, relacionando-se uns com os outros, os homens educavam-se e educavam as novas gerações. [...] Nas comunidades primitivas a educação coincidia totalmente com o fenômeno anteriormente descrito. Os homens apropriavam-se coletivamente dos meios de produção da existência e nesse processo educavam-se e educavam as novas gerações. Prevalecia, aí, o modo de produção comunal, [...] não havia a divisão em classes. Tudo era feito em comum. Na unidade aglutinadora da tribo dava-se a apropriação coletiva da terra, constituindo a propriedade tribal na qual os homens produziam sua existência em comum e se educavam nesse mesmo processo (SAVIANI, 2007, p. 154).

Primitivamente, a acumulação de conhecimentos, gerados no ato produtivo, era transmitida para as gerações posteriores juntamente ao ato de trabalhar. O objetivo final da atividade não era propriamente educar, e sim a reprodução do mundo social. A transmissão do conhecimento era, portanto, assistemática e espontânea. Enquanto os elementos não validados pela experiência produtiva eram afastados, aqueles cuja eficácia fosse comprovada, eram preservados e transmitidos às novas gerações, para garantir a continuidade da espécie e a ascensão do gênero.

Com o advento da apropriação do excedente de trabalho alheio, e a consequente dominação do ser humano sobre o próprio ser humano, a sociedade é dividida em grupos sociais. Passa a ser viável que determinado grupo de seres humanos possa sobreviver sem realizar a atividade trabalho, ou seja, sobreviva graças ao trabalho de outrem. Consequentemente, esse grupo dominante, por não realizar a atividade trabalho, não realiza também a apropriação do conhecimento humano inerente ao processo produtivo, gerando a necessidade de uma formação educativa aparentemente apartada da atividade ontológica humana. O que dá origem à escola.

\footnotetext{
Ora, essa divisão dos homens em classes irá provocar uma divisão também na educação. Introduz-se, assim, uma cisão na unidade da educação, antes identificada plenamente com o próprio processo de trabalho. A partir do escravismo antigo passaremos a ter duas modalidades distintas e separadas de educação: uma para a classe proprietária, identificada como a educação dos homens livres, e outra para a classe não-proprietária, identificada como a educação dos escravos e serviçais. A primeira, centrada nas atividades intelectuais, na arte da palavra e nos exercícios físicos de caráter lúdico ou militar. E a segunda, assimilada ao próprio processo de trabalho. A primeira modalidade de educação deu origem à escola. A palavra escola deriva do grego $\sigma \chi 0 \lambda \dot{\eta}$ e significa, etimologicamente, o lugar do ócio, tempo livre. Era, pois, o lugar para onde iam os que dispunham de tempo livre. Desenvolveu-se, a partir daí, uma forma específica de educação, em contraposição àquela inerente ao processo produtivo (SAVIANI, 2007, p. 155).
}

A escola surge, assim, como forma de humanização supostamente independente da atividade de trabalhar, em uma sociedade que subjuga o trabalho como uma atividade inferior, relegadas a humanos alegadamente de segunda ordem, os escravos. O trabalho era entendido em oposição a liberdade, enquanto o ócio seria a expressão desta. O espaço escolar não se identificava com as necessidades imediatas da vida humana, se destinando à promoção da humanidade em suas capacidades políticas, filosóficas, artísticas, aparentemente dissociadas das necessidades sociais concretas. Assim, a determinação social do trabalho nas sociedades antigas consuma uma suposta 
separação entre educação e trabalho. Porém, esta separação entre educação e trabalho é a aparência de uma separação no interior do próprio trabalho: a divisão do trabalho manual e intelectual.

\begin{abstract}
Por esse ângulo, vê-se que a separação entre escola e produção não coincide exatamente com a separação entre trabalho e educação. Seria, portanto, mais preciso considerar que, após o surgimento da escola, a relação entre trabalho e educação também assume uma dupla identidade. De um lado, continuamos a ter, no caso do trabalho manual, uma educação que se realizava concomitantemente ao próprio processo de trabalho. De outro lado, passamos a ter a educação de tipo escolar destinada à educação para o trabalho intelectual (SAVIANI, 2007, p. 157).
\end{abstract}

No decorrer das transformações sociais, o modo de produção da vida social se modifica, alterando, assim, a forma de realização do complexo educacional. Porém, se mantém a configuração de um processo educativo que ocorre de forma sistemática e intencional, para os destinados a exercer funções intelectuais, e a educação que se realizava concomitantemente ao trabalho, para os grupos que sustentavam a produção do mundo humano. A escola, como local oficial de realização da educação, se manteve, ao longo dos séculos, exclusiva para formação dos futuros dirigentes da sociedade.

Desde suas origens, a escola foi posta do lado do trabalho intelectual, constituindo-se num instrumento para a preparação dos futuros dirigentes que se exercitavam não apenas nas funções da guerra (liderança militar), mas também nas funções de mando (liderança política), através do domínio da arte da palavra e do conhecimento dos fenômenos naturais e das regras de convivência social. Isso pode ser detectado no Egito desde as primeiras dinastias até o surgimento do escriba, assim como na Grécia, em Roma e na Idade Média cujas escolas, restritas, cumpriam a função de preparar os também restritos quadros dirigentes (intelectuais) então requeridos. Nesses contextos, as funções manuais não requeriam preparo escolar. A formação dos trabalhadores se dava com o concomitante exercício das respectivas funções (SAVIANI, 1994, p. 160).

A formação humana prioritária e central era a educação pelo trabalho, realizada de forma assistemática. Já a educação escolar, institucionalizada, era um processo educativo secundário, de forma que sua realização ou não pouco interferiria nos rumos da sociedade. De forma mais clara, explica Duarte (2012, p. 42):

Mas a educação escolar nas sociedades antiga e feudal não se constitui em uma atividade da qual dependa a produção e reprodução material dos seres humanos. [...] a educação escolar permaneceu, naquelas sociedades, como uma forma secundária de educação. A forma dominante da qual dependia a continuidade do processo de produção material da sociedade, continuou a ser, nessas sociedades pré-capitalistas, a educação pelo trabalho. Os homens de cujo trabalho dependia a existência dessas sociedades educavam-se diretamente na atividade laboral.

A partir do século XVI, com um crescimento material insólito realizado pela humanidade, ocorrem revoluções na forma de produção da vida social, impelindo transfigurações em toda estruturação social. Com o aquecimento da atividade mercantil, as cidades começam a ter uma prosperidade inusitada. As necessidades do mercado passam, assim, a estabelecer os rumos da produção, invertendo a antiga ordem de determinantes. A produção do mundo humano, que tinha sido sempre, até então, definida pelas atividades do campo, passa a ser determinada pelas 
necessidades das cidades. A característica pré-capitalista de dependência da cidade em relação ao campo, se inverte na subordinação do campo em relação à cidade (MARX, 1985).

No cerne da prosperidade urbana se encontra a transição da forma de produção artesanal para a manufatureira. Com o advento da manufatura, a produção material do mundo humano passou a ter a interferência de um planejamento intencional e articulado, que ampliava os resultados da produção, a realizando de forma mais eficiente e eficaz. Assim, o intelecto humano é reconhecido como força material. A possibilidade de o ser humano interferir em sua vida concreta, de forma conscientemente orientada, eleva a racionalidade como atributo que possui um poder concreto. Sendo os rumos da sociedade, cada vez mais, conscientemente orientados pela humanidade, e cada vez menos definidos pelos determinantes do mundo natural, o ser humano se percebe como capaz de transformar sua realidade concreta. A partir de sua consciência, de sua razão, a humanidade poderia viver mais e melhor.

Com o crescimento da sociedade urbana, é necessário um patamar mínimo de conhecimento a todos, sendo a família não mais suficiente para essa formação, em um momento em que a Igreja Católica está sendo questionada pela Reforma protestante. A concepção de humanidade, de infância e consequentemente de educação passam por uma revisão necessária para a nova proposta de organização social. A perspectiva humana que se instaura é daquele que quer conhecer e avançar, tendo como modelo o indivíduo que habita a cidade, nos burgos. Com a convicção da possibilidade de a razão interferir na realidade humana, origina-se, na sociedade ocidental, o movimento intelectual conhecido como humanismo, que se caracteriza por uma profunda crença na capacidade da humanidade selar seu próprio destino, a partir do conhecimento que provou propiciar um maior domínio concreto sobre a realidade.

Inaugurando a transferência de um pensamento teocentrista2 para o antropocentrista, o humanismo demarca a possibilidade de formação do ser humano pelos próprios seres humanos, e da possibilidade de sua emancipação: "Como expressão do enfoque humanista, [...] tem-se a emancipação [...], caracterizando-se como uma demanda, como uma necessidade humana de emancipação de dogmas religiosos e de renascimento de valores humanos” (LUIZ, 2006, p. 02). A religião não é posta de lado, mas perde seu caráter monopolista do conhecimento. O ser humano passa a poder ser transformado pelo ser humano, pela via da educação. Como explica Suchodolski (2002, p. 13), "no processo histórico de desenvolvimento do pensamento pedagógico moderno, a prioridade pertence às concepções que atribuem à educação a função de realizar o que o homem deve ser. Como deve ser o homem?”. Assim, urge a necessidade de uma institucionalização, regramento e ordenação do espaço educativo. As propostas pedagógicas modernas possuem como 
norte a formação do devir humano, o ser que irá representar a sintetização das mudanças necessárias para uma nova época.

Até então, em sociedades anteriores, a forma de reprodução do mundo humano mantinha as configurações sociais de forma estáticas. Os seres humanos já nasciam como supostamente deveriam ser. As possibilidades de liberdade dos seres humanos eram, até aquele momento, claramente destinadas a um grupo social específico. Além disso, mesmo para os privilegiados socialmente, os limites da liberdade humana eram conhecidos e preservados. Sabia-se até onde poderiam ir as escolhas concretas da humanidade. Com a modernização, trazendo o conhecimento, o intelecto humano, em proximidade ao trabalho produtivo, alarga-se os limites já conhecidos da emancipação dos seres humanos em relação à natureza e a si mesmos. Tratava-se de uma possibilidade de emancipação trazida pelo conhecimento humano. Desta forma, foi possível perceber que o progresso da vida humana estava sendo trazido pela própria humanidade, sobre os ditames de sua razão. A compreensão da realidade se substancializa sobre a aparência de uma transformação social que se originara na transformação da consciência dos indivíduos. Assim, a emancipação supostamente teria que começar na consciência dos seres humanos, transformando sua individualidade, que transformaria o mundo.

Em vislumbre de uma nova sociedade, se erige a necessidade da constituição de um projeto formativo, que fosse capaz de propor o que a humanidade deveria ser. A educação escolar para todos se instaura como um dos atributos necessários à modernização. A formação espontânea, realizada em exercício, não era mais suficiente para acompanhar as necessidades de humanização que já estavam sendo postas. Uma educação intencional e sistemática começa a se apresentar como necessária para a formação da humanidade que esta nova sociedade exigiria. A formação educativa prioritária para a sociedade começa a ser transferida para um espaço institucionalizado. Se inicia a idealização da escola moderna. Neste meandro, se constitui uma educação intencional e sistemática, de forma que ela pudesse trazer a emancipação da humanidade - a escola é massivamente difundida a partir dessa premissa emancipadora.

\section{Decadência ideológica e educação}

Com o entendimento burguês revolucionário de que a emancipação deveria ser construída no interior de cada indivíduo, e que esta, quando realizada por todos os indivíduos, significaria a emancipação de toda a humanidade, a educação se apresenta como a grande aposta para a construção de uma sociedade livre. Assim, a perspectiva de emancipação pela educação foi sendo aprimorada de diferentes formas, todavia aprofundando a concepção idealista de que a realidade humana seria definida pela consciência humana. A revolução burguesa se realizava sob a 
aparência de estar sendo gerada por uma nova mentalidade humana, sem constatarem, ainda, que essa nova mentalidade apenas emergira devido às transformações concretas que estavam ocorrendo. Desta forma, a convicção de uma consciência transformadora acentua a ideia de uma emancipação que deve ser realizada primeiramente pela consciência, de forma que a educação seria a principal medida a ser tomada para emancipar a humanidade.

Esta ideia de emancipação pela educação, apesar de possuir um viés universal, se erige sobre a base material econômica capitalista. Ainda não estava claro que essa estrutura econômica se sustentava pela exploração de seres humanos pelos próprios seres humanos, pois, até então, seus progressos suplantavam suas contradições. Porém, indubitavelmente, a ascensão da burguesia, como classe dominante, não poderia garantir uma liberdade concreta para todos de forma igualitária. Neste sentido, sua ideologia liberal se mostra contraditória desde o início. Ainda enquanto uma classe revolucionária,

[...] fazia-se presente tanto seu lado ideológico progressista, de defesa da emancipação do ser humano, de crença na razão e na capacidade do homem construir sua história, como também se fazia presente seu lado ideológico mais reacionário, que apontava para a naturalização do social, para alienação das relações entre os seres humanos, para o esvaziamento do indivíduo, para o subjetivismo e o irracionalismo (ARCE, 2002, p. 08).

Desta forma, apesar dos discursos de emancipação estarem recaindo sobre a educação, a institucionalização da educação escolar na sociedade burguesa demonstra sua vinculação com a forma alienada de realização do trabalho. A efetiva concretização da educação escolar para todos emerge junto a contradições características do capitalismo. Por conseguinte, a necessidade de escolarização para as classes trabalhadoras se realiza enquanto as exigências intelectuais do trabalhador se tornavam mais fragmentadas. O conhecimento humano comprovara seu potencial revolucionário ao ser incorporado à produção ao passo que, contraditoriamente, se distanciava da realização do trabalho produtivo. "Os ingredientes intelectuais antes indissociáveis do trabalho manual humano, como ocorria no artesanato, dele se destacam, indo incorporar-se às máquinas" (SAVIANI, 1994, p. 161). O mundo produtivo exigia, portanto, um trabalhador que tivesse acesso a uma educação fragmentada assim como a forma de realização de sua produção.

Neste sentido, a necessidade de escolarização para as classes trabalhadoras não representou uma aproximação entre educação para o trabalho intelectual e a educação para o trabalho manual. O que ocorreu, de fato, foi a divisão no âmbito da escola. Enquanto a educação escolar se generalizava, se evidenciava sua dualidade.

A burguesia e seus intelectuais passaram a discutir que tipo de educação deveria ser dada ao povo, concluindo que este ensino deveria limitar-se ao estritamente necessário; portanto o ideal iluminista de formação do homem pleno ficava totalmente afastado do povo. A burguesia conseguiu a aceitação desta educação restrita por parte do povo com a ajuda da religião, que disseminava, através de seus mestres-escola, a desconfiança sobre o real valor do saber erudito, o qual não teria utilidade para o dia-a-dia das pessoas, que 
exigia o trabalho e a ação, não havendo espaço para as especulações filosóficas de qualquer espécie (ARCE, 2002, p. 201).

Acompanhando o aperfeiçoamento da divisão do trabalho no mundo capitalista, se reforça a divisão da escolarização. Com o desenvolvimento do capitalismo, a escolarização reforça seu caráter dual, dentre a escola para a classe dominante, focada na formação de intelectuais, e a escola para a classe trabalhadora, com uma formação prática, instrumental.

A educação que a burguesia concebeu e realizou [...] não passou, nas suas formas mais
avançadas, da divisão dos homens em dois grandes campos: aquele das profissões
manuais para as quais se requeria uma formação prática limitada à execução de tarefas
mais ou menos delimitadas, dispensando-se o domínio dos respectivos fundamentos
teóricos; e aquele das profissões intelectuais para as quais se requeria domínio teórico
amplo a fim de preparar as elites e representantes da classe dirigente para atuar nos
diferentes setores da sociedade (SAVIANI, 2007, p. 159).

A contradição entre o vislumbrado e o instituído, que já existia desde o início da estruturação capitalista, se tornava cada vez mais evidente. Todavia, as elaborações teóricas sobre o existente ainda se encontravam em fase ascendente, desvelando, mesmo que relativamente, a realidade concreta. A burguesia ainda estava em movimento de libertação da obsoleta ideologia medieval, representando, assim, o interesse de todas as camadas sociais subalternas. Neste contexto se sobressai Hegel (1770-1831), como o último grande pensador da filosofia burguesa revolucionária (LARA, 2013). Em uma base estrutural na qual foi permitido à humanidade se perceber como criadora de sua realidade, a filosofia hegeliana traz, pela primeira vez, a perspectiva de que seria a humanidade, por sua própria atividade (da consciência), a comandarem os rumos da história humana.

O modo de produção capitalista dotou a humanidade de forças produtivas tão desenvolvidas que, pela primeira vez, os homens podem compreender a história como algo feito por eles próprios, e não mais como um destino imposto aos homens pelos deuses ou pela natureza. Hegel dá o primeiro passo, e Marx, algumas décadas depois, o passo conclusivo desta fantástica descoberta: os homens, e apenas eles, são os únicos responsáveis pela sua história. Em outras palavras, a história dos homens seria obra exclusiva deles ao longo do tempo (LESSA 2015, p. 107).

Já tinha sido percebida a possibilidade de a humanidade intervir na realidade, desde o início da modernidade, mas na visão hegeliana a humanidade se torna responsável por todas as transformações sociais ao longo de toda a história. Transformações que eram, supostamente, geradas pela consciência humana. Com isso, consegue explicar, de forma inaugural, toda a história humana, como sendo a história do desenvolvimento do espírito (LESSA, 2012). Assim, a liberdade humana era obra a ser realizada, de forma processual, pela humanidade, oferecendo o caráter histórico e prático desta conquista - conceito de liberdade que posteriormente foi apropriado e aprimorado por Marx (2009). Com a dialética histórica hegeliana se estabelece premissas substanciais para o processo revolucionário, a saber: a sociedade se funda não pelo princípio da identidade, mas pelo da contradição; o verdadeiro é o todo (totalidade); ser é processo (vir a ser); 
o real é racional e o racional é real (HUNGARO, 2008). A atividade humana se eleva como um ponto de destaque nas transformações da própria humanidade, todavia, com o enfoque da realização no plano abstrato das ideias. "Em Hegel [...] apenas o trabalho liberta, mas, além disso, liberta apenas espiritualmente [...] A libertação, como antes, a dominação, tem por eixo o reconhecimento do valor humano; isto é, dá-se no plano de espírito” (VÁZQUEZ, 2007, p. 79). Sendo assim, o filósofo germânico traz a liberdade para o campo de efetivação prática: a partir da atividade humana, a liberdade poderia se integralizar, porém se realizando exclusivamente na consciência.

Hegel nos oferece o primeiro tratamento filosófico profundo da práxis humana como atividade transformadora e produtora de objetos materiais. Nesse sentido desliga-se de seus antecessores idealistas imediatos, que reduzem a prática a um tipo peculiar de atividade da consciência, fundamentalmente moral (VÁZQUEZ, 2007, p. 68).

A evolução do espírito humano parecia ser a fonte do progresso humano. A história da humanidade seria a gradativa tomada de consciência de sua liberdade, e a sociedade burguesa seria a completude dessa libertação. Pois, com a revolução burguesa, a premissa hegeliana afirma que a humanidade finalmente tinha aprendido a "fazer história" (LESSA, 2012). A sociedade burguesa, aparentemente instaurada pela vontade humana, não seria uma sociedade opressora aos indivíduos. Entende, portanto, que a relação entre indivíduo e sociedade não seria mais conflituosa, e sim harmoniosa.

Contudo, a sociedade burguesa se desenvolvia no sentido oposto à harmonia. Apenas crescia a contradição no interior do grupo social revolucionário, que outrora havia representado os interesses da totalidade do povo contra à reação absolutista-feudal. Se estruturava, agora, o proletariado, enquanto classe autônoma, cujos interesses de perpetuar uma luta a favor do povo conflitava com as necessidades da exploração burguesa. Desta forma,

O medo do movimento revolucionário de 1848 interrompe o ciclo progressista da burguesia e de suas possibilidades teóricas em dar respostas que expressassem a visão de mundo ascendente do projeto burguês, pois sua perspectiva teórica choca-se com os limites do projeto de sociedade (LARA, 2013, p. 93).

Com a necessidade de refrear a continuação do movimento revolucionário, que poderia alçar uma sociedade sem classes, a leitura da realidade é posta à serviço de sua conservação: “o pensamento burguês transforma-se numa justificação teórica do existente" (COUTINHO, 2010, p 35). Com a consolidação do capitalismo, a classe burguesa recorre a construções ideológicas que anteriormente precisou superar, negando fundamentos libertários que ajudou a construir.

Na história da filosofia burguesa, é possível discernir - com relativa nitidez - duas etapas principais. A primeira, que vai dos pensadores renascentistas a Hegel, caracteriza-se por um movimento progressista, ascendente, orientado no sentido da elaboração de uma racionalidade humanista e dialética. A segunda - que se segue a uma radical ruptura, ocorrida por volta de 1830-1848 - é assinalada por uma progressiva decadência, pelo abandono mais ou menos completo das conquistas do período anterior, algumas 
definitivas para a humanidade, como é o caso das categorias do humanismo, do historicismo e da razão dialética (COUTINHO, 2010, p. 21).

As teorias burguesas antes revolucionárias são interpretadas de forma conservadora, utilizando análises que enraízam a ideia de que a sociedade burguesa seria a última e insuperável expressão da sociabilidade humana. Os avanços hegelianos sobre a configuração mutável da realidade se estacionam com os chamados hegelianos de direita, que entendem que a humanidade havia alcançado o "fim da história" com a sociedade capitalista (NETTO, 2009). Há, portanto, uma ruptura no interior do pensamento deste teórico.

O pensamento de Hegel dividiu a cultura alemã, no pós-1830, em dois polos. Em torno
de uma de suas afirmações - "o real é racional" - duas interpretações operaram essa
divisão acerca da correta interpretação de Hegel: a primeira que entendia essa elaboração
da seguinte maneira - o real está conforme os desígnios da razão (portanto, é intocável);
e uma segunda interpretação que a entendia da seguinte maneira - o real pode ser
submetido à crítica racional (portanto, passível de ser entendido e transformado). Em
torno da primeira interpretação, juntaram-se os conservadores que foram denominados
como a "direita hegeliana" e ao redor da segunda, os inquietos jovens que ficaram
conhecidos como a "esquerda hegeliana" (HUNGARO, 2008, p. 27-28).

Inicialmente em aproximação da esquerda hegeliana, Marx (2010) se apropria dos avanços hegelianos e, posteriormente, realizando a inversão de sua teoria de acordo com a realidade concreta perpetua o movimento de desvelamento do real. Desta forma, verifica a debilidade do liberalismo burguês, que o encaminharia para a crítica da emancipação política em favor da emancipação humana, e então para o comunismo. Nesse movimento, no qual se sobressai sua parceria com Engels (1820-1895), o pensador prussiano realiza o desenvolvimento de uma teoria capaz de fundamentar cientificamente os interesses do proletariado, explanando as leis fundamentais do capitalismo. Sendo assim, em meio a degradação das ideias burguesas, se inicia a construção de uma teoria revolucionária antagônica à ciência burguesa.

O abismo entre a teoria revolucionária e a teoria burguesa, portanto, começa a se aprofundar. Se tornava evidente a necessidade da subversão do capitalismo para poder se alcançar a emancipação da humanidade, o que, consequentemente, impeliu os retrocessos dos avanços da teoria burguesa que fora um dia revolucionária. "Ou seja, entre a herança teórico cultural emancipadora e a manutenção da ordem, a burguesia opta pelo segundo, dando origem ao 'pensamento da ordem', berço perfeito para o nascimento das ciências sociais especializadas" (LARA, 2013, p. 93). A visão da totalidade é abandonada em nome de uma valorização da especialização compartimentada das ciências. A economia se separa da política, a filosofia se distancia da vida social. Se institui a sociologia como forma de explicar, e apenas explicar, a sociedade utilizando os moldes racionais-empíricos das ciências naturais, o que remete, de certa forma, a uma naturalização da sociedade. No conjunto das elaborações burguesas a missão era, a todo custo, conformar os princípios de liberdade de forma que este coubesse dentro da lógica 
positivista. Caracterizando este período como a decadência ideológica da burguesia, Lukács (1979, p. 99) explica:

\begin{abstract}
A decadência ideológica surge quando as tendências da dinâmica objetiva da vida cessam de ser reconhecidas, ou são inclusive mais ou menos ignoradas, ao passo que se introduzem em seu lugar desejos subjetivos, vistos como a força motriz da realidade. Precisamente porque o movimento histórico objetivo contradiz a ideologia burguesa, mesmo a mais "radical" e "profunda" introdução de tais momentos puramente subjetivos transformar-se-á objetivamente num apoio à burguesia reacionária.
\end{abstract}

Lara (2013, p. 96), se apoiando nos estudos lukacsianos, elenca as seguintes características deste período:

\begin{abstract}
a) a renúncia do pensamento social com preocupações de dar respostas para as mudanças sociais que ocorrem na produção e reprodução da vida social; b) o não questionamento ao capitalismo; c) a desconsideração das descobertas das ciências naturais que questionam os dogmas religiosos; d) o neokantismo e o positivismo como tendências dominantes; e) a filosofia dominante da época é a filosofia de professores e torna-se ciência especializada; f) a filosofia renuncia à sua antiga missão social, cessa de ser expressão, no plano espiritual, dos grandes interesses históricos da burguesia e abandona o problema ideológico; g) o pensamento social como "guarda-fronteira", ou seja, explicação e justificação da vida burguesa; h) a emergência dos intelectuais burocratizados que fazem parte do aparelho do Estado; i) a radicalização da divisão social do trabalho e a emergência dos intelectuais com suas propostas de métodos e independência relativa para suas "ciências".
\end{abstract}

A concepção idealista dialética histórica retrocede para um idealismo a-histórico moralizante, com um neokantismo que recicla valores revolucionários, os mistificando de forma reacionária. A compreensão de liberdade nesta mistificação, além de depender de cada um, seria algo a ser realizado no plano abstrato da consciência e da política. O projeto educativo emancipador é abandonado sendo considerado como já realizado na forma abstrata de cidadania, como decorrência da emancipação política. Caberia a educação não mais transformar a sociedade, mas transformar o indivíduo para que este pudesse servir a esta sociedade. A escola se torna lugar da formação de cidadãos que, teoricamente, seriam emancipados. Neste panorama, um expoente teórico do período de decadência, o sociólogo francês Durkheim (1858-1917), reifica as ideias de Kant para ressignificar a relação entre liberdade e educação.

Já se opuseram a liberdade e a autoridade, como se estes dois fatores da educação se contradissessem e se restringissem. Mas esta oposição e uma falácia. Na verdade, longe de se excluírem, estes dois termos são complementares. A liberdade é filha da autoridade bem aplicada, pois ser livre não significa fazer o que bem entender, mas sim ter autocontrole e saber agir guiado pela razão e cumprir o seu dever (DURKHEIM, 2011, p. 73).

A sua concepção de liberdade neokantiana exalta a moral e o controle interno, destacando o reconhecimento da autoridade como completude da liberdade. Assim, a perspectiva kantiana de educação é aplicada de forma descontextualizada, substituindo sua elaboração sobre a disciplina pela autoridade. Com uma liberdade que se refere a ideia de um dever a ser cumprido, a educação, apesar de estar supostamente a serviço da formação do ser humano para o coletivo, está realizando 
a formação do ser humano que não questiona a realidade. Sendo assim, anteriormente construída sobre a ideia de formar a humanidade para transformar a sociedade, a educação escolar se limita a formar a humanidade para a sociedade. A sociedade capitalista ganha status de irrevogável. Os problemas sociais não aparecem mais como sociais, mas sim dos indivíduos.

A divisão escolar, decorrente da divisão do trabalho, é justificada dentro deste cenário teórico individualista e compartimentado. Com base nesta mistificação ideológica burguesa se exalta a ideia dos talentos individuais, justificando a diferença social devido a uma aptidão pessoal. A expectativa de igualdade é suplantada pela ideia de uma oportuna diferença inata dos indivíduos, que seria importante para a sustentação de uma sociedade complexa como o capitalismo. A diferenciação escolar foi, portanto, justificada e, ainda, considerada desejável, tal como afirma Durkheim (2011, p. 44):

Não podemos nem devemos todos nos devotar ao mesmo gênero de vida; dependendo das nossas aptidões, temos funções diferentes a desempenhar, e é preciso estar em harmonia com aquela que nos incumbe. Nem todos nós fomos feitos para refletir; são precisos homens de sensação e ação. Ao contrário, são precisos outros cujo trabalho seja pensar ${ }^{3}$.

Este pensador demonstra as contradições que existem na atual sociedade, mas se limita exatamente a isso: demonstrar. E ao fazê-lo, procura anunciar uma normalidade que disso decorre, levando a uma conformação com a atual sociedade. As explicações da estruturação social voltam a escapar do controle da humanidade. O motivo de alguns serem privilegiados em detrimentos de outros não seria mais uma ordem divina superior à humanidade, como no antigo regime, mas seria uma ordem "divina" interna aos indivíduos - os talentos inatos. A palavra dom, que se refere a uma perspectiva divina, é substituída pela palavra aptidão, que carrega uma perspectiva biológica. As diferenças sociais estariam nas aptidões individuais. As habilidades desenvolvidas por cada um não seriam mais percebidas como decorrência de uma conjuntura social, mas como resultantes de capacidades supostamente inerentes ao indivíduo.

A educação não forma o homem a partir do nada, como acreditavam Locke e Helvétius, mas se aplica a disposições que já se encontram na criança. De modo geral, pode-se admitir que estas tendências congênitas sejam bastante fortes e difíceis de destruir ou transformar radicalmente, pois dependem de condições orgânicas sobre as quais o educador não tem muito controle. Seguindo este raciocínio, na medida em que estas tendências têm um objeto definido e inclinam o intelecto e o caráter para maneiras de agir e pensar estreitamente estabelecidas, todo o futuro do indivíduo se vê determinado de antemão, e à educação não resta muita coisa a fazer (DURKHEIM, 2011, p. 65).

Ponderando sua perspectiva, Durkheim (2011) afirma que essa predisposição genética se refere a características gerais e vagas, possíveis de serem moldadas. Ou seja, confere à formação humana alguma possibilidade real de formação em si. Entretanto abre o espaço para considerações de fracasso social causados por questões não-sociais. A solução ou a explicação para conflitos 
pessoais e coletivos se encontram numa incapacidade pessoal de conformação a padrões universalmente aceitos. Nesta acepção, explica Tillmann (2002, p. 31):

\begin{abstract}
Durkheim vê na educação um poderoso instrumento de conservação dos padrões sociais já estabelecidos. "Para que serve imaginarmos uma educação que seria fatal para a sociedade que a pusesse em prática?” (Durkheim,1984:10). O que o sociólogo citado não torna claro são os interesses que esta sociedade quer conservar. Ao tratar da sociedade trata como se fosse um espaço de consenso e integração social, não havendo cisões profundas em seu interior, cisões estas denunciadas em Marx e que demonstram a superficialidade da teoria durkheimiana da coesão social. A coesão, integração e consenso são palavras vazias, potencializadas por uma construção educativa capaz de conciliar interesses inconciliáveis.
\end{abstract}

Considerando a sociedade como isenta de questionamento, Durkheim (2011) vê a educação como instrumento de harmonização social. Quanto mais eficiente fosse o processo educativo, melhor seria o desenvolvimento da comunidade em que a escola estivesse. O papel da ação educativa seria formar um cidadão que se tornaria parte do espaço público. Desta forma, o sociólogo francês integra o grupo dos pensadores que defendem os ideais republicanos de uma educação pública, estatal e laica ${ }^{4}$, consolidando a concepção tradicional de educação burguesa.

Neste sentido, se constrói no século XIX o que Saviani (1987) conceitua como a Pedagogia Tradicional, na qual a escola teria a função de difundir a instrução, equacionando o problema da marginalidade e acabando com a ignorância. Ao fundo dessa concepção pedagógica, o impeditivo do indivíduo ser livre não seria ninguém mais do que ele mesmo. A liberdade, tal como é posta, não reivindica uma revolução social, pois o problema não seria a sociedade, e sim o indivíduo. Questões sociais como violência, vícios, corrupção, sucateamento do modo de vida, entre outras, aparecem como problemáticas dissociadas do modo de produção material, relegando ao indivíduo como um problema moral. Com a escola sendo um espaço de construção de caráter e de senso coletivo, os problemas sociais poderiam ser resolvidos nesta esfera.

Entretanto, sem lograr sucesso, esta perspectiva de educação se torna alvo de críticas, proporcionando a busca por uma pedagogia alternativa à tradicional. Porém, com uma percepção imersa na decadência ideológica burguesa, não se admite que o problema da educação está relacionado a sua vinculação a uma sociedade de alienação e exclusão, mas seria sua incapacidade de considerar as diferenças individuais. Com inspiração nos escritos rousseaunianos, o movimento de renovação do ensino Escola Nova (na transição para o século XX), ao criticar a Pedagogia Tradicional, resgata diversos princípios do filósofo iluminista, porém em um contexto no qual suas premissas alimentam a conservação do assim existente. A espontaneidade, a individualidade, a autodeterminação, que outrora foram revolucionários, por carregarem significados opostos à ordenação feudal, acomodam de forma complacente a ideologia burguesa.

Neste caminho, no qual a compreensão do desenvolvimento individual é superestimada, há o crescimento da vinculação entre a perspectiva educacional com disciplinas biológicas, 
psicológicas, antropológicas. A formação humana se volta para uma compreensão do ser humano destacado da sociedade. Formar o ser humano passa a se referir, primeiramente, a seu desenvolvimento psicofísico. De forma confluente, os pensadores em educação do início do século XX são, predominantemente, médicos e psicólogos, com Montessori (1870-1952), Decroly (18711932) e Claparéde (1873-1940) em destaque. Vale lembrar que suas obras foram de fundamental importância para questões até então negligenciadas, tais como o direito à educação para pessoas com deficiências, o respeito pelos interesses trazidos pelos estudantes, e a substituição de um espaço escolar opressivo por um motivador. Se caracteriza, assim, o modelo escolanovista, que buscaria uma remediação da sociedade.

Essas esperanças fundamentavam-se na convicção de que as crianças cuja infância
decorre numa boa atmosfera educativa em casa e na escola se tornarão homens de valor,
homens equilibrados, capazes de reparar o mal deste mundo social onde terão que viver.
Desempenhou aqui um papel decisivo o mito tradicional do renascimento social através
da educação da nova geração (SUCHODOLSKI, 2002, p. 72).

Se aprofunda a perspectiva salvacionista da educação, no qual seria necessário adequar os métodos de ensino para se formar seres humanos que resolveriam as mazelas da sociedade. Sendo assim, o cerne da questão educacional assume um outro extremo, deslocando-se o foco social para o individual, porém mantendo mistificada a raiz do problema formativo - a forma de realização do trabalho na sociedade capitalista. Por conseguinte, termina por agravar as questões ao invés de resolvê-las. Concisamente, Saviani (1987, p.21) denuncia que essa nova concepção de educação

tenha deslocado o eixo da questão pedagógica do intelecto para o sentimento; do aspecto
lógico para o psicológico; dos conteúdos cognitivos para os métodos ou processos
pedagógicos; do professor para o aluno, do esforço para o interesse; da disciplina para a
espontaneidade; do diretivismo para o não-diretivismo; da quantidade para a qualidade;
de uma pedagogia de inspiração filosófica centrada na ciência da lógica para uma
pedagogia de inspiração experimental baseada principalmente nas contribuições da
biologia e da psicologia. Em suma, trata-se de uma teoria pedagógica que considera que
o importante não é aprender, mas aprender a aprender.

Entra em foco os estudos evolutivos, de aptidões naturais individuais, da formação da inteligência, dando suporte ao desenvolvimento dos testes para avaliar as capacidades cognitivas de um sujeito (conhecidos como quociente de inteligência ou, simplesmente, QI). Entende-se que cada indivíduo tem seu ritmo para aprender, por isso é importante os testes, para selecionar, classificar e direcionar até onde cada um poderia ir em seu desenvolvimento. Com isso, há um silenciamento das questões sociais nas ciências relativas à educação. A centralidade do processo educativo se volta para o estudante e em seu desenvolvimento para viver e conviver em sociedade. O indivíduo que fracassa seria aquele não desenvolveu suas aptidões - o problema a ser resolvido é biológico e individual. Neste ideário biologizante a liberdade se insere na possibilidade de cada um expressar-se e desenvolver-se o melhor possível dentro de suas aptidões fisiológicas e psíquicas. 
Assim, se transporta o eixo de preocupação do âmbito político (relativo à sociedade em seu conjunto) para o âmbito técnico-pedagógico (relativo ao interior da escola), além de realizar o afrouxamento da disciplina e a despreocupação com a transmissão de conhecimentos, rebaixando o nível do ensino destinado às camadas populares (SAVIANI, 1987). Pois, com a preocupação em resolver o problema da marginalidade resultante de estudantes que não se adaptavam ao regime educativo tradicional, contraditoriamente aprofundam essa marginalidade, por "dar força à ideia segundo a qual é melhor uma boa escola para poucos do que uma escola deficiente para muitos" (SAVIANI, 1987, p. 22).

Por um caminho mais próximo às questões sociais, John Dewey (1859-1952) busca pensar uma educação que pudesse intervir nas crescentes contradições do sistema capitalista; porém sobre os fundamentos liberais burgueses. Desta forma, o também expoente do movimento Escola Nova, propõe elementos de uma escola ativa, que representa sua esperança de alcançar a verdadeira democracia. "A sociedade almejada por Dewey é a democracia, um modo de vida cooperativo em que todas as definições advêm de consensos obtidos mediante livre e aberta participação de todos” (CUNHA, 2001, p. 89). Para isso, seria importante a formação do ser livre, que, segundo sua explicação:

Relativamente à liberdade, o importante é ter-se em mente que ela designa mais uma atitude mental do que a ausência de restrição exterior de movimentos, mas que esta qualidade espiritual não pode desenvolver-se sem grande produção de movimentos para os atos de explorar, experimentar, aplicar, etc. (DEWEY, 1959, p. 337).

O pedagogo estadunidense expressa o ideário liberal num contexto em que as barreiras políticas e econômicas, contra a qual a burguesia lutou, já estavam decaídas, no entanto a liberdade ainda não tinha sido alcançada por todos. Tendo o sistema burguês como definitivo, o problema da liberdade se volta para uma questão espiritual, condizente ao indivíduo, que precisava de uma formação diferente da tradicional, para construir esse estado de liberdade. Para isso, era preciso um processo de controle sobre uma suposta natureza humana.

Já se presumiu, muitas vezes, explicita ou inconscientemente, que as tendências do indivíduo são, por seu natural, puramente individualistas ou egoístas, e, portanto, antissociais. Regulação ou controle denota então o processo pelo qual ele é levado a subordinar seus impulsos naturais aos fins públicos ou comuns (DEWEY, 1959, p. 25).

O trecho acima demonstra sua crença numa natureza humana que seria egoísta e, portanto, não passível de modificação, mas de regulação. Por meio da educação, cada indivíduo seria capaz se de autorregular, não sendo necessário um Estado regulador. Entende que o bemestar do coletivo se coloca como mais vantajoso do que os interesses individuais, assumindo que seria inevitável a contradição entre interesses individuais e o coletivo. Seu ideal de mundo se vincula, assim, ao bem-estar social, porém cabendo à consciência de cada indivíduo o levar a agir em prol deste bem comum. 
Sobre as questões de classe, Dewey (1959) se preocupava em garantir a mobilidade social, pela educação: “compete ao meio escolar contrabalançar os vários elementos do ambiente social e ter em vista dar a cada indivíduo oportunidade para fugir às limitações do grupo social em que nasceu, entrando em contato vital com um ambiente mais amplo" (DEWEY, 1959, p. 22). Neste sentido, ao aclamar uma sociedade mais justa e igualitária, coloca o indivíduo e suas capacidades como promotores desta. Mesmo demonstrando um profundo interesse na igualdade social - o que lhe rendeu ser "acusado" de ser comunista -, não propõe um modelo social que divirja do capitalismo. $\mathrm{Na}$ verdade, sua proposta estabelece uma hierarquia democrática pela hierarquia das capacidades, ou seja, a meritocracia - categoria que, inclusive, vem a se tornar base de posteriores reformas no sistema educacional. Sua orientação escolar buscava a eliminação das questões de classe pela educação, no entanto sem problematizar essas questões. Via, na educação, a possibilidade de elevar em todos os estudantes as capacidades necessárias para viver com dignidade. Sua tentativa era capacitar para que todos pudessem, harmonicamente, conviver, dando como consolidadas e irrevogáveis as bases econômico-sociais.

A perspectiva de Dewey (1959) oferece um panorama importante para a manutenção do capitalismo, ao aproximar a realidade social e a prática pedagógica não pela crítica, mas pela via da meritocracia e do pragmatismo. Como decorrência, a partir da segunda metade do século XX, as ideias deweyanas são apropriadas e restringidas, junto a interesses em prol da reestruturação produtiva capitalista. Se inicia elaborações pedagógicas que Saviani (1987) classifica como Pedagogia Tecnicista, que torna a proposta deweyana mais superficial. Enquanto Dewey (1959) se ocupava em aproximar a realidade social como um todo, o tecnicismo se ocupa em aproximar apenas âmbito mercadológico e empresarial da realidade. Nesta pedagogia o professor assume uma condição de técnico, e o importante não é só aprender a aprender, aprender a viver e a conviver, mas também aprender a fazer. A tentativa ainda é manter a educação no posto de redentora social, em um silenciamento das contradições do modo de produção capitalista. Desta forma, retoma-se o foco de atuação pedagógica para o professor, porém tornando ainda mais rarefeito os conteúdos escolares, peneirando o conhecimento de forma a trabalhar "apenas o que importa". Assim, a pedagogia tecnicista advoga a reconfiguração do processo educativo de maneira a torná-lo objetivo e operacional.

Neste aprofundamento da educação escolar em uma relação de serventia ao capitalismo os mesmos princípios que foram derrubados para a revolução burguesa foram "ressuscitados" com uma nova roupagem. Por exemplo, o fim da aceitação de um sistema de privilégios determinados pelo nascimento, parecia ser a esperança de igualdade entre os homens. Entretanto, os privilégios da hereditariedade ainda são centrais na atual sociedade moderna, visivelmente no 
direito à propriedade privada. Um homem que possui essa propriedade deixa para seus herdeiros essa posse. Em lugar da aristocracia, a meritocracia, sendo um "mérito" decisivo ter nascido em uma família com abastados recursos materiais. Neste prosseguimento, diversos fatores socioeconômicos que favorecem a prosperidade de alguns em detrimento à grande massa população são revestidos pelo discurso de serem frutos de um suposto mérito individual.

A meritocracia é uma categoria, portanto, que perpassa a responsabilização. Ela está na base da proposta política liberal: igualdade de oportunidades e não de resultados. Para ela, dadas as oportunidades, o que faz a diferença entre as pessoas é o esforço pessoal, o mérito de cada um. Nada é dito sobre a igualdade de condições no ponto de partida (FREITAS, 2012, p. 383).

Com a ideologia da meritocracia sendo utilizada para explicar uma vida de sofrimento relegada à maioria da população, a educação é posta como o instrumento de salvação da sociedade. Num claro movimento de retomada conservadora, a ideologia da meritocracia ganha força no senso comum educacional, sendo utilizada para explicar os sucessos, concedidos a poucos, e os sofrimentos, relegados à maioria da população. Por considerar que o problema não seria a sociedade, e sim o indivíduo, o tecnicismo entende que a escola teria uma importante missão: capacitar os indivíduos para se incluírem no sistema social.

Nessa perspectiva, se desenvolve uma base ideológica perversa para o sistema educativo, a dizer: o mundo teria várias oportunidades para pessoas esforçadas e bem capacitadas se tornarem bem-sucedidas, e a escola estaria perdendo tempo ao trabalhar conteúdos teóricos que não seriam úteis para a atuação real desses indivíduos, que precisam aprender desde cedo como podem se adequar à composição da sociedade. Em outras palavras, a principal preocupação dos jovens deveria ser como estes podem vender sua força de trabalho da melhor forma possível.

Neste sentido, a perspectiva de emancipação pela educação começa a ser resgatada, porém corrompendo o significado da própria emancipação. Sendo assim, retoma-se o discurso de uma educação "emancipatória" pregando que aqueles que conseguissem prosperar no mercado de trabalho seriam "emancipados", pois poderiam usufruir das melhores produções humanas, com poder de escolha sobre como viver. Uma vida de miséria, violência, corrupção seriam resultados de "más escolhas" de indivíduos, que não foram "bem instruídos". Isto porque cada um teria condições de construir uma vida livre desses males, a partir de um currículo organizado por competências, habilidades e atitudes. Uma emancipação individual, como aposta para a concretização de uma sociedade melhor, se torna consenso nas propostas educacionais. Esta emancipação

[...] está relacionada ao crescimento individual e pessoal, baseada num sujeito abstrato, cujas mudanças passam por um posicionamento individual no qual a pessoa toma atitudes e "contamina" os outros à sua volta, provocando um círculo de mudanças, [...] emancipação significa a emancipação da consciência. A emancipação é 
autoemancipação. É o sujeito que tem de se emancipar. Já que não se pode mudar a sociedade, mude-se cada indivíduo (CURADO SILVA, 2008, p. 97).

Neste sentido, é preciso retomar que, sendo o trabalho a categoria fundante da humanidade, conteúdo da própria essência humana, a expectativa de emancipação deve estar profundamente vinculada a forma de realização desta atividade. Nas palavras de Saviani (1994, p. 152), “o homem, para continuar existindo, precisa estar continuamente produzindo sua própria existência através do trabalho. Isto faz com que a vida do homem seja determinada pelo modo como ele produz sua existência". Portanto, para a esfera da educação escolar apenas é possível realizar a "emancipação" quando esta é entendida pelo liberalismo burguês, pois, para a emancipação bumana, na compreensão marxiana, é necessária a revolução político-econômica. Com o horizonte de uma sociedade comunista, não cabe a proposta (burguesa) de um indivíduo isolado se emancipar, independentemente das condições materiais da sociedade em que este se insere.

Dentro desta perspectiva, o problema da liberdade e emancipação se encontra nas bases materiais de produção social, o que cerceia o papel da educação na transformação social. E assim, fica claro que não cabe à educação operar a emancipação da humanidade. No entanto,

A arma da crítica não pode, é claro, substituir a crítica da arma, o poder material tem de ser derrubado pelo poder material, mas a teoria também se torna força material quando se apodera das massas. A teoria é capaz de se apoderar das massas tão logo demonstra ad hominem, e demonstra ad hominem tão logo se torna radical. Ser radical é agarrar a coisa pela raiz. Mas a raiz, para o homem, é o próprio homem (MARX, 2010, p. 151, grifos do autor).

A educação não ser capaz de promover uma mudança estrutural não implica sua total falta de perspectiva revolucionária. Não se considera que a educação pode realizar a emancipação da humanidade, mas pode criar condições necessárias para esse fim. Sendo assim, não se desconsidera o papel da educação em uma sociedade que, essencialmente, se refere à formação humana. Inclusive considera-se que o sistema escolar que foi sendo construído no interior do capitalismo constitui-se como um aprimoramento da forma de se realizar a educação, ainda que, contraditoriamente, servindo à alienação dos determinantes históricos da sociedade burguesa. Nesta perspectiva, utiliza-se as palavras de Duarte (2012, p. 45):

Assinalado e frisado que a reflexão aqui apresentada não faz abstrações da contraditoriedade do processo histórico na sociedade capitalista, retomo a afirmação de é um avanço histórico-ontológico, no que diz respeito à formação dos seres humanos, o fato de que a educação escolar tenha se tornado a forma socialmente dominante de educação.

A humanidade formada pela sociedade capitalista, em seu sistema escolar, possui maior possibilidade de apropriação da realidade do que a humanidade outrora formada diretamente pelo trabalho, nas sociedades servis e escravocratas. Que nos remete à “concepção de Marx, de que a humanidade tem se desenvolvido, tem se humanizado, por meio das sociedades marcadas pelas relações sociais alienadas" (DUARTE, 2012, p. 45). Desta maneira, constata-se que o capitalismo 
exigiu um maior grau de apropriação da realidade concreta, para a perpetuação do modo de produção do próprio sistema capitalista. Uma necessidade que abre, em suas contradições, brechas subversivas.

\section{Longe de uma conclusão...}

É verdade que o conhecimento escolar a ser transmitido e apropriado se origina na forma social burguesa, porém isto não retira seu caráter revolucionário, quando tratado em suas raízes históricas. Pois, historicamente, sua gênese se vincula à necessidade de clarificar o real, rechaçando qualquer formulação mistificante. A questão problemática não é a produção do conhecimento que se deflagrou junto a uma burguesia revolucionária, mas seu estacionamento, ocultação e desvirtuamento em contexto pós-revolucionário. Assim, a apropriação do conhecimento e da cultura burguesa, quando realizados de forma radical, caminham em direção contrária a uma "burguesização". Neste sentido, se busca a reafirmação do conhecimento científico, sem negar que se trata de uma herança burguesa.

Por este motivo vale o esforço de analisar como se realizar a educação escolar, valorizando o conhecimento como seu objeto central. Defende-se que a revolução comunista se vincula ao conhecimento de uma forma especialmente peculiar pois, diferentemente da revolução burguesa, a superação do sistema capitalista possui a especificidade de exigir uma subjetividade que desenvolveu um alto grau de conhecimento objetivo. "A vitória das forças burguesas contra o mundo feudal não exigia um conhecimento objetivo da realidade histórica e social [...]. O proletariado pelo contrário, foi colocado pela história diante da tarefa de uma transformação consciente a realidade" (LÖWY, 1998, p. 132). A apropriação do conhecimento objetivo sobre o real se configura, portanto, como fomento à formação de uma consciência capaz de perceber o todo e compreender suas mediações - uma consciência revolucionária. A consciência revolucionária possui, assim, uma sincronia em relação ao conhecimento, demonstrando a junção subversiva entre classe proletária, conhecimento e consciência.

Com isso, não se afirma que o conhecimento teórico seria o suficiente para a revolução social e, assim, a emancipação humana. A perspectiva marxiana entende que a passagem da teoria à realidade requer a mediação de uma prática social, que seja "teórico-prática: teórica sem ser mera contemplação, já que é a teoria que guia ação, e prática, ou ação guiada pela teoria” (VÁZQUEZ, 2007, p. 144). Ao se retomar o conhecimento sobre a realidade como o objeto da educação, essa se torna um dos componentes da revolução. É importante frisar esta parte: um dos componentes da revolução. Afinal, a perspectiva marxiana centraliza a práxis como transformadora do real, pois "a teoria mais revolucionária nunca deixa de ser mera teoria enquanto não se realiza ou se 
materializa em atos" (VÁZQUEZ, 2007, p. 158). Por isto importa destacar os sujeitos históricos a realizarem, efetivamente, a revolução que poderá emancipar a humanidade. Sendo assim, a práxis revolucionária demanda o aporte teórico revolucionário em conjunção ao sujeito que realiza a sustentação material do mundo social. Como pode ser visto em Marx (2010, p. 156-157, grifos do autor):

Assim como a filosofia encontra suas armas materiais no proletariado, o proletariado encontra na filosofia suas armas espirituais, e tão logo o relâmpago do pensamento tenha penetrado profundamente nesse ingênuo solo do povo, a emancipação dos [...] homens se completará. [...] A cabeça dessa emancipação é a filosofia, o proletariado é seu coração. A filosofia não pode se efetivar sem a suprassunção [Aufhebung] do proletariado, o proletariado não pode se suprassumir sem a efetivação da filosofia.

Sendo o conhecimento sobre o mundo social um elemento revolucionário, que Marx (2010) aponta como sendo a filosofia, trata-se, então, de considerar a educação como a viabilizadora desse componente necessário à emancipação. Um componente crucial, porém, insuficiente quando isolado da práxis.

O proletariado não pode emancipar-se sem passar da teoria à práxis. Nem a teoria por si mesma pode emancipá-lo nem sua existência social garante por si só sua liberação. É preciso que o proletariado adquira consciência de sua situação, de suas necessidades radicais e da necessidade e condições de sua libertação. Essa consciência é justamente a filosofia; mais exatamente, sua filosofia (VÁZQUEZ, 2007, p. 118).

Em outro extremo, uma prática que se retroalimenta pela própria prática, também não poderia ser, jamais, revolucionária. Pois, é substancial um maior grau de conhecimento objetivo sobre a sociedade, a fim de se possibilitar a compreensão dos nexos constitutivos do real, para além de explicações simplistas que contribuem para a alienação. Portanto, compreender que a educação não pode ser responsabilizada pela emancipação humana significa entender, também, que sem esta a perspectiva de mudança se distancia. Não é a educação a força motriz da história, mas a própria humanidade - bumanidade que é formada em diversas esferas, dentre essas, o processo educacional. Assim, a especificidade da formação humana a ser realizada na educação escolar encontra sua brecha subversiva devido à sua autonomia relativa somada à sua função ontológica.

Nesta acepção, caberia a processos formativos escolares possibilidades de auxiliar na formação do sujeito revolucionário para a luta emancipadora. Entende-se, desta forma, que a expectativa de emancipação humana cabe à educação quando em uma perspectiva de formação de consciência crítica revolucionária. Os esforços engendrados na esfera da educação se baseiam em formar o indivíduo o mais consciente possível dentro dessas condições contraditórias, o que seria substancial para a luta pela emancipação humana.

Com esta perspectiva, a função da educação escolar se encontra na formação da humanidade da forma mais radical possível, ou seja, a busca pela humanização, que é negada pela configuração social do trabalho no sistema capitalista. Uma educação escolar revolucionária tem, 
portanto, a pretensão da formação humana que resgata o sentido ontológico de ser humano - o ser que tem a possibilidade concreta de transformar a realidade na qual se encontra, sendo capaz, inclusive, de construir uma sociedade para além do capitalismo.

\section{Referências}

ARCE, Alessandra. A pedagogia na "era das revoluções": uma análise do pensamento de Pestalozzi e Froebel. Campinas: Autores Associados, 2002.

COUTINHO, Carlos Nelson. Estruturalismo e miséria da razão. $2^{\mathrm{a}}$ ed. São Paulo: Expressão Popular, 2010.

CUNHA, Marcus Vinícius da. John Dewey e o pensamento educacional brasileiro: a centralidade da noção de movimento. Rev. Bras. Educ. [online], n.17, p. 86-99, mai/ago 2001. Disponível em: <http://www.scielo.br/pdf/rbedu/n17/n17a06.pdf>. Acesso em 23 dez. 2015.

CURADO SILVA, Kátia A. Curado P. Cordeiro. Professores com formação stricto sensu e o desenvolvimento da pesquisa na educação básica da rede pública de Goiânia: realidades, entraves e possibilidades. 2008. 292 p. Tese (Doutorado em Educação) Faculdade de Educação, UFG, Goiânia, 2008.

DEWEY, John. Democracia e educação. São Paulo: Companhia Editora Nacional, 1959.

DUARTE, Newton. Lukács e Saviani: a ontologia do ser social e a pedagogia histórico-crítica. In: SAVIANI, Dermeval; DUARTE, Newton. Pedagogia histórico-crítica e luta de classes na educação escolar. Campinas: Autores Associados, 2012. p. 37-57.

. A formação do indivíduo e a objetivação do gênero humano. 1992. 238f. Tese (Doutorado em Educação) - Faculdade de Educação, Universidade Estadual de Campinas, Campinas, 1992.

DURKHEIM, Émile. Educação e sociologia. Petrópolis: Ed. Vozes, 2011.

FREITAS, Luiz Carlos de. Os reformadores empresariais da educação: da desmoralização do magistério à destruição do sistema público de educação. Rev. Educação e Sociedade, Campinas, v. 33, n. 119, p. 379-404, jun. 2012.

HUNGARO, Edson Marcelo. Trabalho, tempo livre e emancipação humana: os determinantes ontológicos das políticas sociais de lazer. 2008. 264p. Tese (Doutorado em Educação Física) - Faculdade de Educação Física, Universidade Estadual de Campinas, Campinas-SP, 2008.

KONDER, Leandro. A construção da proposta pedagógica do SESC Rio. Rio de Janeiro: Ed. SENAC Rio, 2000.

LARA, Ricardo. Notas lukacsianas sobre a decadência ideológica da burguesia. Rev. Katálysis, Florianópolis, v. 16, n. 1, p. 91-100, jan/jun, 2013.

LESSA, Sérgio. Para compreender a Ontologia de Lukács. São Paulo: Instituto Lukács, 2015.

. Introdução à ontologia de Lukács: aspectos históricos e ontológicos. Brasilia: Programa de Pós-graduação em Educação Física - PPGEF/UnB. 2012. 5 Discos Digitais de Vídeo (DVD). 803min.

LIMA, Marteana Ferreira de. Trabalho, reprodução social e educação em Lukács. 2009. 128p. Dissertação (Mestrado em Educação) - Programa de Pós-Graduação em Educação, Universidade Estadual do Ceará - UECE, Fortaleza, 2009.

LÖWY, Michael. As aventuras de Karl Marx contra o Barão de Münchhausen. São Paulo: Cortez, 1998.

LUKÁCS, György. Marx e o problema da decadência ideológica. In: Marxismo e teoria da literatura. Rio de Janeiro: Civilização Brasileira, 1979. 
LUIZ, Danota Estrufika Cantoia. Emancipação e Modernidade: elementos para uma discussão. Serviço Social em Revista (Online), v. 9, n. 1, p. 01-20, jul/dez 2006. Disponível em:

<http://www.uel.br/revistas/ssrevista/c-v9n1_danuta.htm> Acesso em 16 dez. 2015.

MARX, Karl. Crítica da filosofia do direito de Hegel - Introdução. In: Crítica da filosofia do direito de Hegel. São Paulo: Boitempo Editorial, 2010.

Para a questão judaica. São Paulo: Expressão popular, 2009.

. Manuscritos econômico-filosóficos. São Paulo: Boitempo editorial, 2008.

A miséria da filosofia. São Paulo: Global, 1985.

MARX, Karl; ENGELS, Friedrich. A ideologia alemã. São Paulo: Expressão Popular, 2009.

NETTO, José Paulo. Prólogo à edição brasileira. In: MARX, Karl. Para a questão judaica. São Paulo: Expressão popular, 2009.

SAVIANI, Dermeval. Trabalho e educação: fundamentos ontológicos e históricos. Revista Brasileira de Educação, v. 12, n. 34, p. 152-165, jan./abr. 2007.

. O trabalho como princípio educativo frente às novas tecnologias. In: FERRETTI, C. J. et al. (Org.). Novas tecnologias, trabalho e educação: um debate multidisciplinar. Petrópolis: Vozes, 1994. p. 151-168.

. Educação: do senso comum à consciência filosófica. São Paulo: Cortez Editora; Autores Associados, 1989.

. Escola e democracia: teorias da educação, curvatura da vara, onze teses sobre educação e política. São Paulo: Cortez, 1987.

SUCHODOLSKI, Bogdan. A pedagogia e as grandes correntes filosóficas: a pedagogia da essência e a pedagogia da existência. São Paulo: Centauro, 2002.

TILLMANN, Reinaldo. Emancipação e subordinação: duas teorias educativas no mundo do trabalho. Rev. Sociedade em Debate, Pelotas, 8(1):5-18, p. 19-36, abr. 2002.

VÁZQUEZ, A. Sánchez. Filosofia da práxis. São Paulo: Expressão Popular, 2007.

\footnotetext{
Notas

${ }^{1}$ Doutora e Mestre em Educação pelo programa de pós-graduação em Educação da Universidade de Brasília. Possui Licenciatura Plena em Educação Física pela Universidade Federal do Rio de Janeiro, e é especialista em Psicopedagogia, pela Universidade Católica de Brasília. Professora do Instituto Federal de Brasília, Campus Brasília. ORCID: http://orcid.org/0000-0001-84251269 Email: fernanda.lima@ifb.edu.br

${ }^{2}$ Teoria segundo a qual Deus é o centro do universo, sendo a humanidade apenas um instrumento Dele. Com o humanismo, o teocentrismo é substituído pelo antropocentrismo, no qual se centraliza o ser humano como determinador de sua própria vida e da sociedade. Não se nega Deus, mas se considera que Ele proporciona maior liberdade para a humanidade designar seu próprio destino.

${ }^{3}$ Contrastando diretamente com a prerrogativa marxiana por uma sociedade no qual o ser humano "cace de manhã, pesque de tarde, crie gado à tardinha, critique depois da ceia, tal como me aprouver, sem ter de me tornar caçador, pescador, pastor ou crítico" (MARX; ENGELS, 2009, p. 49), Durkheim (2011) sugere uma "natural" unilateralidade da aptidão de cada ser.

${ }^{4}$ Continuando o retrocesso dos valores revolucionários burgueses, esses pilares têm sido, atualmente, alvo de ataque. Hoje, no Brasil, assistimos a retomada da religião como parâmetro para a formação humana, que propicia uma educação privada de financiamento particular.
} 